\title{
The triptych of conceptual modeling
}

\section{A framework for a better understanding of conceptual modeling}

\author{
Heinrich C. Mayr ${ }^{1}\left[\right.$ (I) Bernhard Thalheim² ${ }^{2}$
}

Received: 23 September 2020 / Accepted: 23 September 2020 / Published online: 27 November 2020

(c) The Author(s) 2020

\begin{abstract}
We understand this paper as a contribution to the "anatomy" of conceptual models. We propose a signature of conceptual models for their characterization, which allows a clear distinction from other types of models. The motivation for this work arose from the observation that conceptual models are widely discussed in science and practice, especially in computer science, but that their potential is far from being exploited. We combine our proposal of a more transparent explanation of the nature of conceptual models with an approach that classifies conceptual models as a link between the dimension of linguistic terms and the encyclopedic dimension of notions. As a paradigm we use the triptych, whose central tableau represents the model dimension. The effectiveness of this explanatory approach is illustrated by a number of examples. We derive a number of open research questions that should be answered to complete the anatomy of conceptual models.
\end{abstract}

Keywords Conceptual modeling · Modeling languages $\cdot$ Model characteristics $\cdot$ Model hierarchies $\cdot$ Language hierarchies . Concept $\cdot$ Notion $\cdot$ Term

\section{Introduction}

Perception and abstraction, i.e., "modeling," and reasoning on models are basic human capabilities for coping with, understanding, and influencing the environment. Over time, many types of modeling have evolved: from completely intuitive to highly controlled ones that apply a specific set of terms forming the semantic instruments of a (modeling) language.

Natural language enables us to describe, communicate, or understand perceptions and thus supports a moderately controlled modeling: the language elements (words, phrases, texts, icons), their composition, and meaning are tacitly agreed upon by the users and, to a certain degree, are shared among them. The assignment of meaning to language elements, however, is sometimes ambiguous, and the syntactical rules are not strict throughout. Elements, syntax, and interpretation change over time.

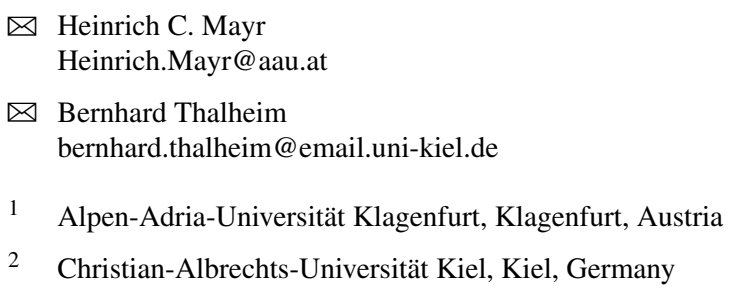

In contrast to that, scientific disciplines, in particular mathematics, introduce strict formal languages and propose semantic interpretations to the lexical elements and their syntactic composition. An illustrative example of such a formal approach is the Petri Net Language as initially introduced by Petri [1]: a special type of bipartite directed graphs is provided together with some composition rules, and a family of functions ("marking" and "transition"). Applying standard Linear Algebra mechanisms to this leads to a powerful calculus. However, this calculus has no semantics at all! In order to make Petri Nets usable for modeling, we need to provide a "net interpretation," i.e., to associate semantics to the language elements. Most popular is to interpret one type of nodes (the places) by Conditions and the other type by Events. The marking functions then describe possible situations by means of valid or invalid conditions; the transition function describes occurrence of events and their consequences.

In natural or technical sciences, this approach is reversed: initially, a conceptualization ${ }^{1}$ of the domain of interest is

\footnotetext{
$\overline{1}$ https://www.webster-dictionary.org/definition/conceptualisation (accessed on August 3, 2020): "A conceptualization is an abstract, simplified view of the world that we wish to represent."
} 
established and subsequently one or more (textual and/or graphical) languages are defined for representing its elements and relationships. Think for instance of a conceptualization of electrical components that are represented using electrical circuit diagrams. The Unified Modeling Language UML comes with a conceptualization of abstract elements like class, attribute, relation, state, and activity for describing domains of interest. Similarly, the Business Process Model and Notation BPMN comes with a conceptualization of abstract elements like actors, activities, or decisions. A branch of Knowledge Engineering deals with so-called action languages that are based on the claim that "action theories always model-explicitly or implicitly—-the general notions of time, change and causality" [2].

Often, such languages are called "conceptual modeling languages" and their use as "conceptual modeling"-although despite countless attempts, there is no generally used strict definition of what constitutes conceptual modeling and what does not.

One group of such definition attempts are variants of "Conceptual Modeling is Modeling with Concepts" [3, 4], and

- introduce these concepts via more or less rigid ontological frameworks, or by simple explanation using natural language; $[5,6]$ called this latter approach "a priori semantics"

- propose more or less formalized constructs for representation, i.e., a 'modeling language'

- and often call the approach "semiformal" an awful wording per se as it just indicates, that the proposed framework does not fulfil the criteria demanded for a consistent calculus that can be used for correctness proofs, etc.

This way of defining "conceptual modeling," however, does not provide hard criteria for differentiating it from other modeling methods in individual cases. For example, most conceptual modelers would say that programming or relational database design is not conceptual modeling (see, e.g., [7]). Nevertheless, programming languages or the SQL DDL work with conceptualizations, the latter for instance featuring elements like "Relation" or "Attribute" that have some basic semantics and therefore might be seen to be concepts in the above definition's sense. From a practical point of view, this open question is not a real problem. However, the term "Conceptual Modeling" is widely used, and there has been an international conference with this name for 39 years. Therefore, it would be desirable to have a definition or at least a set of criteria at hand that would allow us to define more precisely what is and what is not a conceptual model. We will return to this question in Sect. 4.

Recent initiatives (e.g., $[4,8,9])$ try to compile and analyze systematically existing definitions and opinions in order to filter out a better understanding of the nature of conceptual modeling. Mylopoulos [7] offers "three complementary theses, answers to the question 'What is a conceptual model?'." These theses essentially state that conceptual models are (1) computational because they are stored in computers and are analyzed and justified by computers, (2) artifacts, so they should have requirements dictated by Engineering, and (3) social artifacts, because they must capture the common conceptualization of a group.

In fact, from the very beginning, conceptual modeling was propagated as a means to improve the design and implementation of whatsoever software system, especially with regard to a comprehensive and as clear as possible elicitation and analysis of system requirements. Until now, however, the practical use has mostly taken place at the level of mere drawings, which do not play a major role in the further development process and are rarely adapted to changes. Consequently, the developed software (nota bene: again a model) usually deviates considerably from what was originally modeled. The situation in Business Process Modeling is not much different, independent of the modeling method used (like BPMN, Adonis, Event Chains, etc.). This means that the potential of conceptual modeling is far from being exploited.

MDA/MDSD approaches [10] and models@ runtime [11] are enforcedly more aligned with the system life cycle as they use the models for generating or driving the targeted software. Usually, they work with well-defined subsets or variants of known modeling methods [12-14]. However, also these approaches do not have a breakthrough in practice.

Worse still, university graduates who highly motivated join a company often quickly lose their enthusiasm when they are told that modeling is too expensive in terms of effort and cost, not paid for by the customer, and has no impact on the quality of the software development process, since "agile developers" know what they are doing.

We assume that all this is mainly due to the fact that inventors and propagandists of conceptual modeling languages like ourselves have so far failed to make the anatomy of conceptual modeling and its benefits transparent to users. Instead, we invented hundreds of variants of "modeling languages" always believing that it should be a must for the targeted user to acknowledge and happily exploit the miracle we presented to her/him. Moreover, uncountable papers present what they call "ontologies" and expect the readers to internalize and share these without contradiction. Others implicitly equate conceptual modeling with "graphical modeling" [15] and thus not only add to the confusion but also distort the view of the essential.

We believe, therefore, that in order to make conceptual modeling more attractive for practitioners, we have (1) to provide a clear conception of what we are speaking about, (2) to make the anatomy of conceptual modeling transparent with its principles, paradigms, postulates, assumptions, par- 
ticularities, specifics, potential, capacity and limitations, and (3) to allow the modelers to easily create and use their own domain and culture tailored modeling language and method instead of forcing them to learn and deal with ours.

With this paper, we would like to make a contribution to these To-do's. We offer here our understanding of what modeling, in particular, conceptual modeling is about, and how we can clearly distinguish it from other modeling approaches. The perspective presented reflects four decades of dealing with conceptual modeling in research and practice, countless discussions with colleagues and practitioners, the rich body of knowledge published up to now, as well as long and intensive working meetings the authors had over the last two years. But we have neither the intention to improve the world nor to provide an $n+1$ st definition of what "conceptual modeling" is. Rather, we present a "signature" of conceptual modeling in the sense of a framework of characteristics by which conceptual modeling can be categorized. In other words, we will offer an explanatory framework that could help to better understand the nature of conceptual modeling.

The paper is structured as follows: Sect. 2 explores specifics of models and introduces six characteristics that can be observed for models. Section 3 refines these six characteristics in terms of a list of criteria that can be used to determine the nature of $\mathrm{CM}$ (conceptual modeling). In Sect. 4, we summarize the two previous sections and discuss the first conclusions that can be drawn from them. This will provide the basis for Sect. 5, where we present the core message of the paper: the triptych paradigm of conceptual modeling together with its dimensions and model/language hierarchies. The paper ends with a conclusion and an outlook on open research challenges in Sect. 6.

We will reference related work where appropriate but, intentionally, there will be no separate section on related work. Instead, we refer to the rather comprehensive overview given in Thalheim [4], to [23] and to attempts to define the term "model" [17].

Finally, we would like to point out that, for the sake of readability, we also adopt the usual homonymous use of the term "model" in this paper: from an epistemological point of view, a model is a mental object. In practice, however, the representation of a model introduced into the perceivable world is also referred to as a model, like, e.g., an EntityRelationship diagram. We adopt this homonymy because the particular meaning will result from the respective context.

\section{Characteristics of models}

Across disciplines, the number of publications dealing with models, modeling, and abstraction is unmanageable. Even for the notion of "conceptual model" more than 60 different definitions can easily be found $[4,7,23]$. None of these, however, allows for a robust and unequivocal differentiation between conceptual and non-conceptual models. This is also true for an interesting definition that recently emerged in a side-piece discussion at ER 2017: "A conceptual model is a partial representation of a domain that can answer a question." For, it only highlights one aspect.

We, therefore, try to elaborate the essence of conceptual modeling in the form of a taxonomy of characteristics that may help to better delimit the semantics of the term "conceptual model."

Before we can do this, we first need to take a closer look at the terms "concept", "notion", and "term". The reader will have noticed that we have avoided their use as much as possible so far. The reason for this is that the meanings of these terms in literature and in encyclopedias are not sharply delineated so that there are overlapping or synonymous definitions. For the purposes of this paper, however, we need a more precise distinction (which will be further specified in Sect. 5). We, therefore, assume the following meanings in the subsequent sections:

- A Concept is a mental construct formed by mentally combining characteristics of general or abstract ideas gained by cognition. It is seen as a pair of an intension and its extension. The intension describes the concept as such, the extension consists of all objects that might be used as an example for the intension. This definition is based on [22] (a concept is "something conceived in the mind"), Wordnet [24] ("an abstract or general idea inferred or derived from specific instances"), and the Stanford Encyclopedia of Philosophy ${ }^{2}$ ("concepts are constituents of thoughts"), $[3,25,26]$.

- A Notion is a general inclusive concept in which some confidence is placed; i.e., a notion is a specific kind of concept. ${ }^{3}$ This definition is based on Wordnet ("a notion is a general understanding, vague idea or a general inclusive concept in which some confidence is placed") and [22] who propose "arriving at the notion of law" as an example for the interpretation of notion as a general inclusive concept.

- A Term is an item of a (possibly formal) language formed for denoting, designating, or naming something. "Language" is understood here in a very broad sense, i.e., it can be textual, graphical but also material. Terms can refer to concepts and/or represent them for recognition by linguistic perception processes, i.e., processes mapping a

\footnotetext{
2 https://plato.stanford.edu/entries/concepts/.

3 With this interpretation notion corresponds to the German "abstrakter Begriff" [58] as "mental and abstract reflection of a class of individuals or classes on the basis of their invariant characteristics ... i.e. specific concepts as abstract essences ... (ideas)."
} 
term/symbol to a mental object. Note that this interpretation of term is inspired by one of the definitions given in [22] ("a pronounceable series of letters having a distinct meaning especially in a particular field"), but differs from others. We use it here to clearly separate "term" from "concept" and "notion." Also, for the sake of clarity, we will not use any other word with a similar meaning throughout the paper (such as for example "sign").

Second, as conceptual models are models, we have to agree on the key characteristics of models before specializing and extending these to determine what the characteristics of conceptual models are. For this purpose, we adopt the main criteria provided by Mahr [27] that may be summarized by " $A$ model is the synthesis of a conceptual idea, a form of expression and the assumption of a role through which it fulfils a function."

Model Characteristic 1: Models are related to (a collection) of "origins" or "originals". A model is a model of something, ${ }^{5}$ i.e., it is a proxy of a natural, artificial, or mental original; in particular, the original of a model may be a model itself. As originals may change in time, the model/original relationship may change in time as well [28]. Models are results of cognitive processes (perception) [5]. The mission of a model is that of transporting a "cargo," namely the perceived properties of the original that are considered to be relevant within the perception's context. Mahr sees this function as the key criterion for a "model being a model" [29]. The transport occurs with the usage of the model; precision and transport warranties distinguish models and metaphors [30].

Model Characteristic 2: Concern and usage. We distinguish three different main concerns that are coupled to most kinds of modeling: (1) understanding, (2) communicating, and (3) agreeing as a process of consolidation, manifestation, and consensus. With the usage, a model unfolds its power: "We place models between ourselves as perceiving, recognizing, understanding, judging or acting subjects and the world as perceptible, observable, effective, to be judged or produced exterior. The impact of models results from the role that models play through their transport function in work processes, cognitive processes, business processes. The power of

\footnotetext{
${ }^{4}$ Original quotation in German: "Ein Modell ist die Synthese einer begrifflichen Vorstellung, einer Ausdrucksform und einer Einnahme einer Rolle, durch die es eine Funktion erfüllt." Bernd Mahr cites here George A. Millers work "The science of words," which was not accessible for us directly [34].

5 "Every mental phenomenon has an object toward it is directed" [57].
}

models is the result of their power to act"6,7 [27]. In general, the usage of a model will be directed by its initial concern. However, this is not mandatory, because the using individual can do what she/he wants with a model.

Model Characteristic 3: Purpose and function. Given its concern and usage, a model serves a particular purpose: to understand/analyze/assess the origin, to plan/design a new original, to explain or predict properties of the original, to communicate about perceptions and ideas, and similar. The usage determines the function(s) of a model, for example to support explanation. It therefore makes sense to see a model's function as that of an "instrument" $[16,18]$.

Model Characteristic 4: Domain and context. For the concerns of modeling, we distinguish the following three domains:

(a) the domain of interest, experience, and perspective of a human,

(b) the application domain or world domain to which a community of practice refers,

(c) the domain of discourse among some particular people.

The first domain is concerned with understanding and thinking. So is the second one which additionally is concerned with realization (in the sense of implementation). The third domain is concerned with communication.

A model is created, modified or refined in particular contexts: the personal context of the modeler, the environmental context in which the modeling process takes place, the social context, i.e., the particular community of practice, and the spatio-temporal context (time, duration, location, and movement, etc.) [31, 32].

Clearly, a model's cargo as well as its interpretation depends on the given concern, purpose, domain and context.

Model Characteristic 5: Focus. A model reflects, for a given purpose, the "relevant" but not all aspects of its origin(al). In particular, "The objectual properties may recede behind the consideration of their rational-functional relationships" [33]. Note, that this is a more general view than that of [28], who emphasizes on reduction, i.e., differentiates between

\footnotetext{
${ }^{6}$ Original quotation in German: "Wir stellen Modelle zwischen uns als wahrnehmende, erkennende, verstehende, urteilende oder handelnde Subjekte und die Welt als wahrnehmbares, beobachtbares, wirkendes, zu beurteilendes oder herzustellendes Äußeres. Die Wirkungsmacht von Modellen ergibt sich aus der Rolle, die Modelle durch ihre Transportfunktion in Werkprozessen, Erkenntnisprozessen, Unternehmensprozessen spielen. Die Macht von Modellen ist das Ergebnis ihrer Wirkungsmacht."

7 Translated with www.DeepL.com/Translator.
} 
"modeled attributes" and "neglected attributes" of the origin(al).

Model Characteristic 6: Representation. For communication/transportation purposes, a model needs an associated "physical" representation; examples are an acoustic signal, a toy railroad, a diagram, a XML statement, an OWL file, a spoken/written natural language text, and so forth. These representations allow models to be recognized and understood by communication partners; in the case of a human partner, recognition is enhanced by "linguistic perception" [5]. The representations should be dependable, understandable by the involved actors (humans and/or systems), and thus be agreed within the community of practice. George A. Miller explained the relationship between a model and its representation as follows: "To have a model means to be able to produce or recognize a physical symbol carrier that represents a model, and to understand the meaning of the model" [34].

Clearly, this taxonomy is not complete, as the literature addresses many more characteristics. For example, see the "Kiel house of modeling" [17]. ${ }^{8}$ However, it should not be a problem to classify most of them in relation to the characteristics presented.

\section{Characteristics of conceptual models}

Conceptual models are models, conceptual modeling is (a kind of) modeling. Consequently, the characteristics described in Sect. 2 also apply to conceptual models. So we need to identify what constitutes the specialization "conceptual." To this end, we will now, wherever possible, specialize the above model characteristics and introduce two more that we believe are specific to conceptual models.

CM Characteristic 1: Conceptual models are related to (a collection of) origins or originals. As there is no restriction on the entirety of origin(al)s conceptual models may relate to, this characteristic does not provide an indication for differentiation.

CM Characteristic 2: Concern and usage. In the discipline of Informatics the term "Conceptual Modeling" has been initially used for a database design method, later on for requirements modeling and since the 90 s for business process modeling and software specification. In all cases, the mapping from conceptual models (represented using languages like the ERM, UML, BPMN, SysML, etc.) to an implemented system language (SQL DDL, programming languages, workflow languages, etc.) has been a key issue until today. Model Driven Software Development (MDSD)

\footnotetext{
${ }^{8}$ https://bernhard-thalheim.de/ModellingToProgram/.
}

[35], Model Driven Architecture [10] as well as models@runtime [11] all start from conceptual models and aim at materializing and automating that mapping. Model Centered Architecture (MCA) [36] advocates, for any aspect of a system under development, the use of Domain Specific Modeling Languages (DSML), i.e., focuses on models (and their metamodels) in any design and development step up to the running system. In summary, conceptual modeling has a strong (although not mandatory) orientation to a subsequent implementation/realization of artifacts or products. It, therefore, is widely used as a means for requirements modeling and analysis. Consequently, we may add the concern (4) "specifying" to the list of concerns. Unlike [7], however, we do not claim that conceptual models are "computational"-and that they have only existed since computers have existed.

CM Characteristic 3: Purpose and function. As a consequence of extending the concern, we supplement the purpose "plan/design a new original" with "plan/design/realize."

CM Characteristic 4: Domain and context. There is no principal limitation regarding domains and contexts of conceptual modeling so that also this characteristic provides no hard criterion for differentiation. However, in practice, conceptual modeling has been mainly used so far in domains and contexts that deal with discrete objects (things, actions), their properties and relationships. Again, however, this is no strong criterion for differentiation.

CM Characteristic 5: Focus. Conceptual models have no noteworthy peculiarity regarding this general model characteristic. In practice, however, their focus has been mainly on aspects that can be realized or implemented.

CM Characteristic 6: Representation. Conceptual models transport semantics by terms that denote concepts. As terms are elements of languages, conceptual modeling uses linguistic representations in the broadest sense: these may originate from a diagrammatic language (e.g., ER diagrams), a natural language, an artificial language (e.g., XML), a mathematical or formal language (e.g., Petri nets in the sense of algebraic structures). Such languages provide a set of literals and a set of rules for composing literals to terms, terms to phrases, phrases to sentences, and so on. If the members of a certain community of practice have agreed on the meaning of terms or patterns and their combination, they can infer from these to the transported concepts.

CM Characteristic 7: Concept Space. From its beginnings, conceptual modeling had a strong relation to semantics. Partly, "semantic modeling" using terms that are associated with concepts from a "concept space" is even used as a synonym [37] of conceptual modeling: A community of practice agrees on the terms and concepts, which it will consider, as 
well as on the association between these terms and concepts, and thus establishes an instrument for communication. The terms used for representing models thus have a meaning, the "a priori semantic" [6].

So we can consider conceptual models as models that are "enhanced" by concepts from a concept space. I.e., the decision to compile and accept a set of concepts and to use its elements for relating them to models opens the entrance into the world of conceptual modeling (we will discuss this in detail within the next chapters). This characteristic governs all others and reminds to the definition "Conceptual Modeling is modeling with concepts" cited in the introduction. Reflecting the considerations presented so far, a more apposite description could be "Conceptual Modeling is modeling with concepts from an associated concept space."

Such association provides a semantical basis supporting understanding communicated models within a community of practice (see CM characteristic 2): as a prerequisite, this community agrees in advance on a set of concepts to be used for modeling, their meaning and representation (controlled vocabulary). Usually, this is done informally in natural language, i.e., relating an explaining natural language phrase to the given concept. As an example think of Peter Chen's explanation of the concepts "entity" and "relation" [38]: "An entity is a 'thing' which can be distinctly identified. A specific person, company, or event is an example of an entity. A relationship is an association among entities. For instance, 'father-son' is a relationship between two 'person' entities." I.e., the semantics of natural language-and thus its intrinsic a priori [39-41] knowledge-are used to determine (the meaning of) concepts.

Therefore, the degree of a common understanding of the elements of a concept space by the members of a community of practice depends on the degree of equivalence of their understanding of the natural language used. As such equivalence cannot be formally derived or proven without a reference mechanism like an ontology or a set of axioms, the "a priori semantics" [5] of conceptual models provide a practically useful but formally inaccurate means for communication. Some people, therefore, call conceptual models "semiformal" as has been mentioned in the introduction.

CM Characteristic 8: Concept relationship. Concepts can be related to each other. Typical concept relationships are the "abstractions" [42] Mereology (Aggregation), Generalization, and Intension, each of them having an inverse: Disassembly (into components), Specialization (by additional concept attributes), Extension (denominating the elements characterized by their intension concept) [43, 44]. Other concept relationships are, e.g., synonymy, homonymy, troponymy, hyponymy; however, these only concern the level of assigning linguistic denoters to concepts. Therefore, such relationships can be found in thesauri and encyclopedias, since they occur at the linguistic level.

Note that a conceptual modeling language that offers explicit means for modeling the intension/extension relationship, ${ }^{9}$ supports "multi-level" modeling. For, models then are not mere extensions of a given metamodel but may consist themselves of intension/extension concept hierarchies. In the field of Domain Specific Modeling, this possibility is often neglected: Metametamodel abstraction relations are just used for relating metamodel concepts, but metamodels often do not explicitly provide such relations for allowing the same on the modeling level, i.e., the relationships are not introduced as part of the concept space in question.

Table 1 summarizes these considerations on model characteristics.

\section{Some initial results of using the characteristics}

In this section, we use some examples to show how the previously introduced $\mathrm{CM}$ characteristics can be used to decide for a given model whether it is conceptual or not.

First, however, we note that models based on model hierarchy frameworks such as the Information Resource Dictionary IRDS [45]) or the MetaObject Facility MOF [46] are not conceptual per se, although the model hierarchies are induced by concept relationships according to $\mathrm{CM}$ characteristic 8 . For, a metamodel (on a hierarchy level $H^{n+2}$, e.g., on MOF Level M2) specifies modeling elements ("modeling concepts" in [47]) and their relationships but neither automatically nor explicitly associates these with a concept space in the sense of CM Characteristic 7. This would also not change if we cast the whole thing in languages, i.e., create linguistic means of expression for the formulation/representation of models on level $H^{n+1}$ or model extensions on level $H^{n}$ by defining corresponding grammars. ${ }^{10}$

The Entity-Relationship Model (in the sense of a metamodel) thus only becomes "conceptual" when the meaning of the terms "entity set," "relationship set," "attribute," etc. is at least colloquially explained (a priori semantics) in an associated concept space. The same applies to the metamodel of the UML. In other words, modeling with UML is conceptual if the a priori semantic explanation of what is meant by "class,"

\footnotetext{
${ }^{9}$ Intension/Extension are the concept relationships establishing model hierarchies with levels like metametamodel I metamodel I model I instance as provided, e.g., by the OMG MetaObject Facility [46] or the ISO Information Resource Dictionary System [45].

10 Please note that we use a more general form of model hierarchy here, which can have any number of levels, possibly even nested ones. For practical purposes, especially for system design, the MOF or IRDS levels are of course sufficient, i.e., $n=0$ in this case.
} 
Table 1 Characteristics of models and conceptual models

\begin{tabular}{|c|c|c|}
\hline Characteristics & Model & Conceptual Model \\
\hline Relation to origins & \multicolumn{2}{|c|}{ A (conceptual) model is a model of something } \\
\hline Concern and usage & $\begin{array}{l}\text { 1. Understanding } \\
\text { 2. Communicating } \\
\text { 3. Agreeing }\end{array}$ & $\begin{array}{l}(1)-(3)+(4) \\
\text { specifying }\end{array}$ \\
\hline Purpose and function & $\begin{array}{l}\text { 1. Understand, } \\
\text { analyze, assess } \\
\text { 2. Plan, design } \\
\text { 3. Explain, explore, } \\
\text { predict, use }\end{array}$ & $\begin{array}{l}(1)-(3)+(4) \\
\text { realize }\end{array}$ \\
\hline \multirow[t]{9}{*}{ Domain and context } & \multicolumn{2}{|l|}{ Domain } \\
\hline & \multicolumn{2}{|c|}{$\begin{array}{l}\text { 1. Domain of interest, experience, and } \\
\text { perspective of a human }\end{array}$} \\
\hline & \multicolumn{2}{|c|}{$\begin{array}{l}\text { 2. Application domain or world domain } \\
\text { accepted by a community of practice }\end{array}$} \\
\hline & \multicolumn{2}{|c|}{ 3. Domain of discourse among some people } \\
\hline & \multicolumn{2}{|l|}{ Context } \\
\hline & \multicolumn{2}{|c|}{ 1. Personal context of the modeler } \\
\hline & \multicolumn{2}{|c|}{$\begin{array}{l}\text { 2. Environmental context in which the } \\
\text { modeling process takes place }\end{array}$} \\
\hline & \multicolumn{2}{|c|}{$\begin{array}{l}\text { 3. Social context, i.e., the particular } \\
\text { community of practice, and }\end{array}$} \\
\hline & \multicolumn{2}{|c|}{ 4. Spatio-temporal context } \\
\hline Focus & $\begin{array}{l}\text { Aspects of the } \\
\text { origin(al) that are } \\
\text { "relevant" for a } \\
\text { given purpose }\end{array}$ & $\begin{array}{l}\text { Not mandatory but } \\
\text { lived practice: } \\
\text { aspects that can be } \\
\text { realized or } \\
\text { implemented }\end{array}$ \\
\hline Representation & $\begin{array}{l}\text { By physical symbol } \\
\text { carriers }\end{array}$ & $\begin{array}{l}\text { Lived practice: (in } \\
\text { the broadest } \\
\text { sense) linguistic } \\
\text { terms }\end{array}$ \\
\hline Concept space & & $\begin{array}{l}\text { Is associated with } \\
\text { concepts from a } \\
\text { concept space: } \\
\text { a-priori semantics }\end{array}$ \\
\hline Concept relationship & & $\begin{array}{l}\text { Semantic } \\
\text { relationships } \\
\text { between concepts } \\
\text { induce semantic } \\
\text { relationships } \\
\text { between } \\
\text { conceptual models }\end{array}$ \\
\hline
\end{tabular}

"relation," etc. is associated with the models. Pure drawing of diagrams or "graphical modeling" is not conceptual.

But what about the question we raised in the introduction: "Is the Relational Data Model a conceptual one?" Traditionally, answering this question was avoided by introducing the notion of "logical" model, i.e., a representation that is based on a "logical" language and the semantics defined by usage (or implementation). Mylopoulos [7] makes a more specific statement on this: "Relational schemas are not conceptual as well, because they say nothing about the meaning of data in a database, only about its structure." At first sight, one seems to be able to get along with this statement, but we do not want to accept it as a generally valid one. For, the situation is identical to the situation described above regarding UML: if there is (within the given community of practice) a common accepted view on the meaning of the terms "relation," "column," "row," "attribute," and so forth, the Relational Data Model (a metamodel) is a conceptual model, as its elements have an associated concept space. A relational schema represented in SQL DDL (on level $H^{1}$ ) and introducing common concepts (e.g., a table called "client") then allows us to infer that client is an extension of the concept relation and has attributes (columns) describing clients' properties, and rows describing particular clients.

If, at this stage, we chose the names of the columns from denominators that are well-known in our natural language NL (e.g., name, birthday ...) then we can exploit the NL a priori knowledge in order to intuitively interpret the tables. This was already recognized in the year 1977 by John and Diane Smith [42]: "Since databases are usually designed to model the real world as we understand it, we can safely require that all object names in a relation definition be natural language nouns. These nouns then provide the bridge between our intuitive understanding of the real world and its intended reflection in the relation definition. If natural language nouns are not used, any discussion of the meaningfulness of a relation definition seems moot." Formally, however, these $H^{1}$ level concepts become related to the respective Universe of Discourse only, if the respective denominators ("client," "name," etc.) and their a priori semantics are added to the concept space. This is often achieved by the use of a data dictionary or by establishing an ontology.

Another question that sometimes gives our students headaches is: "What is a balance sheet from a modeling perspective?" Of course, our students first would ask us to specify more precisely, what we mean by "balance sheet":

1. The usual components (concepts) of a balance sheet and their interrelationships as taught in a lecture on business administration, i.e., something that could be considered a metamodel, hierarchy level $H^{2}$ ?

2. The balancing scheme of a company $\mathrm{C}$, on the basis of which balance sheets for $\mathrm{C}$ can be drawn up at any reporting date, i.e., something that could be regarded as an extension of (1) and thus as (the representation of) a model, hierarchy level $H^{1}$ ?

3. The balance sheet of enterprise $\mathrm{C}$ as of 31.12 .2019 , i.e., something that could be regarded as an extension of (2) and therefore as (the representation of) a model, hierarchy level $H^{0}$ ? 
So far so good. But now we ask: Is a balancing scheme according to (2) a conceptual model? Again, this question can be answered with the help of the characteristics: Yes, it is a conceptual model, if the underlying metamodel associates with its elements the concept space of business administration with concepts like "assets", "liabilities", "cash on hand", "equity capital", "borrowed capital", etc. and their relationships.

A somewhat easier to answer question than the previous one concerns the Petri nets already mentioned in the introduction: are they conceptual models? Again, for answering the question we have to specify more precisely, what we are concretely referring to by the term "Petri net." So let us restrict ourselves to the classical "marked Petri Net."11 Given the definition in the footnote, we are dealing here with a purely formal structure with which no semantics are associated. However, if we associate, as Petri suggested, a "net interpretation," i.e., a concept space, with (the elements of) the marked Petri Net it becomes a conceptual model. This, by the way, on hierarchy level $H^{n}$, since a change of marking leads to a new extension. On $H^{n+1}$, one could, as an example, consider $(\mathrm{P}, \mathrm{T}, \mathrm{I}, \mathrm{O})$ together with the set of all possible mappings $\mathrm{M}$ as the intension of the $H^{n}$ model.

Comparable considerations can also be made about circuit diagrams in electrical engineering. It should be clear that such a diagram is not a pure drawing or formal graph structure but the graphical representation of a planned circuit or the description of a realized circuit. In the German term "Schaltplan" (literally translated as "circuit plan") this model character is clearly expressed. The diagram for a concrete circuit is located on hierarchy level $H^{0}$, but of course $H^{1}$ plans are also common as intensions, namely when they are generic, so that several concrete extensions can be derived from them (see Fig. 1). But are circuit diagrams also conceptual models? We can answer this question clearly with yes: The metamodel uses concepts exclusively from the concept space of electrical engineering (power source, resistor, line, switch, lamp, etc.), the (graph-)grammatical composition rules for the symbols of the model representation language correspond to the physical rules of concept space's universe of discourse. Thus, the model in Fig. 1 represents a conceptual model for circuits in which a lamp and a switch are connected in series to a Battery as a power source.

Another example concerns a temple stele (Fig. 2) that is over 3000 years old, about which historians say the following: Basically, this is the "material manifestation" (a representation) of the contexts of a religious imagination. The stele

\footnotetext{
11 A Marked Petri Net is a quintuple $(P, T, I, O, M)$, where $(P, T, I, O)$ is a bipartite graph with disjoint node sets $P$ and $T$ and two relations $I, O \subseteq P \times T$ such that $0<|P \cup T|<\infty$ and $(P \cup T, I \cup O)$ is a connected graph; $M: P \rightarrow N_{0}$ is a mapping called marking $\left(N_{0}\right.$ denoting the set of natural numbers including 0 ).
}

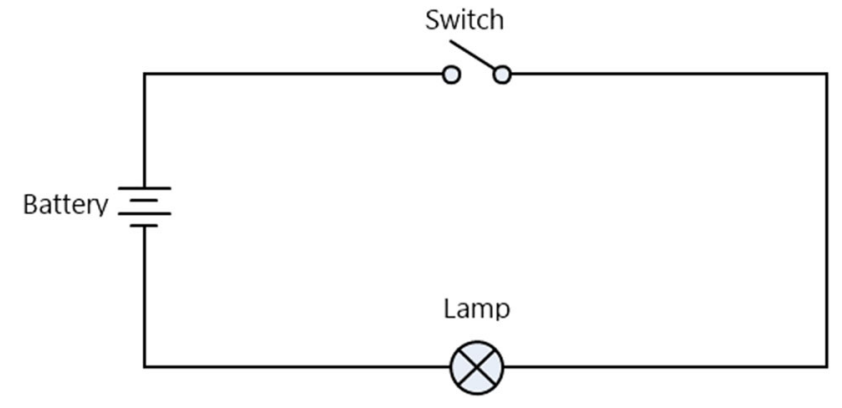

Fig. 1 Simple circuit diagram

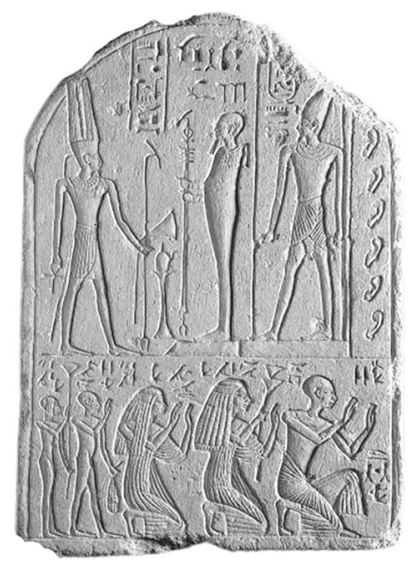

Fig. 2 Stele of Seth-er-neheh, Roemer- und Pelizaeus-Museum, Hildesheim

represents a religious concept that was new at the time, namely a God who hears and answers to prayers (see the ears on the right side of the picture), with the king acting as "mediator." In addition, social conditions are described: In the group of adorants, the stele founder comes first, then his wife, then their children, ranked by age (importance). Clearly, the stele represents a model of abstract and concrete originals (Char. 1). Its concern and usage is communicating the new religious concept to viewers (Char. 2) with the purpose (Char. 3) that these understand the concept. The focus (Char. 5) is on the idea of a listening God, the representation is graphical with some symbols referencing concepts. We interpret this stele as the representation of a hierarchy $H^{1}$ level model, as at least God and king may have various extensions. If this model is a conceptual one, cannot be said with a hundred per cent certainty. For there is no explicitly assigned concept space with corresponding concept relations handed down with. However, it is not impossible that artist and viewers were aware of such a concept space at the time.

For our last example, think of a musical score. This is a linguistic representation of the (complex) model created by a composer using a common musical language. Members of the musical community that has agreed on the meaning of 
terms or patterns and their combination of the musical language can infer from the score elements and their sequence to the transported concepts. For instance, think of "The Art of the Fugue" by Johann Sebastian Bach. In this case, the score represents a conceptual model. This model in turn may have many different extensions (created, e.g., through performances).

To sum up, the existence of a concept space is a precondition for models being conceptual ones; the degree to which a component of a conceptual model has UoD related, interpretable semantics depends on its associated vocabulary elements. For comparison, consider the difference between WEB 1.0 and WEB 3.0 ("Semantic Web" [21]): In WEB 1.0 we can interpret website content based on the natural language terms used exploiting NL's a priori knowledge. WEB 3.0 pages are intended to provide a vocabulary defining the semantics of the page content; consequently, WEB 3.0 pages are representations of conceptual models (mainly on hierarchy level $H^{0}$ ), the concept space being defined, e.g., exploiting schema.org [48].

\section{The triptych: dimensions of conceptual modeling}

Our considerations as presented so far have inspired us to create a paradigm for conceptual modeling, namely the triptych $^{12}$ : For with this paradigm the transition from the linguistic description of phenomena to modeling and then to conceptual modeling can be described vividly through the successive opening of wings. In this section, we first explain the paradigm and then go into detail about the three dimensions that we attribute to conceptual modeling with this paradigm.

\subsection{The paradigm}

\section{The closed triptych: the intuitive perspective}

Let us start with the closed triptych as depicted in Fig. $3^{13}$ : we see the backs of the two outer wings, which in this state cover the middle tableau. Let us associate this situation with the everyday situation of dealing with information without explicit conceptualization and modeling: humans reason on the basis of their observations on the perceivable world due to their senses, feelings, and beliefs. They build their mental worlds based on their perceptions which typically differ.

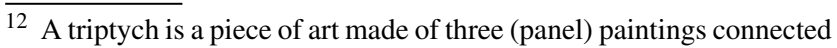
to each other in a way that allows the two outer ones to fold in toward the larger central one (see https://dictionary.cambridge.org). I.e., when folded, the inner panel is not visible.

13 We are well aware of the fact that we cannot match the artistic skills of the painters of real triptychs.
}

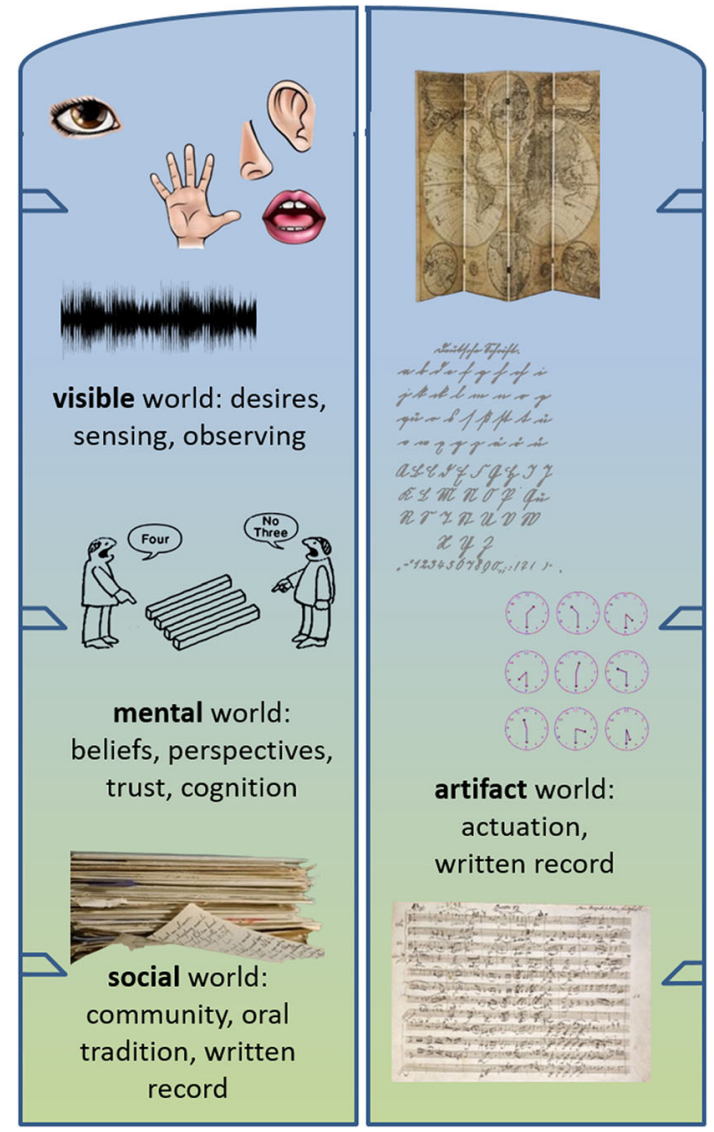

Fig. 3 The two tableaus of the closed triptych: Languages (right) enabling the narrative representation of observations, mental reasoning and social agreement (left)

They live in their social worlds with their agreements. On the other side, humans use a variety of languages as an instrument for narrative representations. The "enabling language tableau" on the right-hand side shows us, that we can use very different languages. The "sensing, mental and social tableau" on the left-hand side symbolizes the diversity of aspects and things that can be grasped and communicated through language: (i) observations, (ii) beliefs, perspectives, trust, and cognition, and (iii) agreements.

\section{The triptych with its right wing opened: the model per- spective}

When we open the right wing, we see its front side and at the same time the right half of the previously hidden middle tableau as is depicted in Fig. 4. This opens the way to modeling: on the now visible part of the middle tableau, we see models of different levels of abstraction (meta ${ }^{n}$-models and their extensions down to the (lowest) meta ${ }^{0}$-level, the instance level). Their origins are the elements on the backside of the closed left (sensing, mental and social) tableau. The message of the right tableau remains the same, except that we are now dealing not only with natural languages and tradi- 
Fig. 4 The triptych with its right wing opened and left wing closed

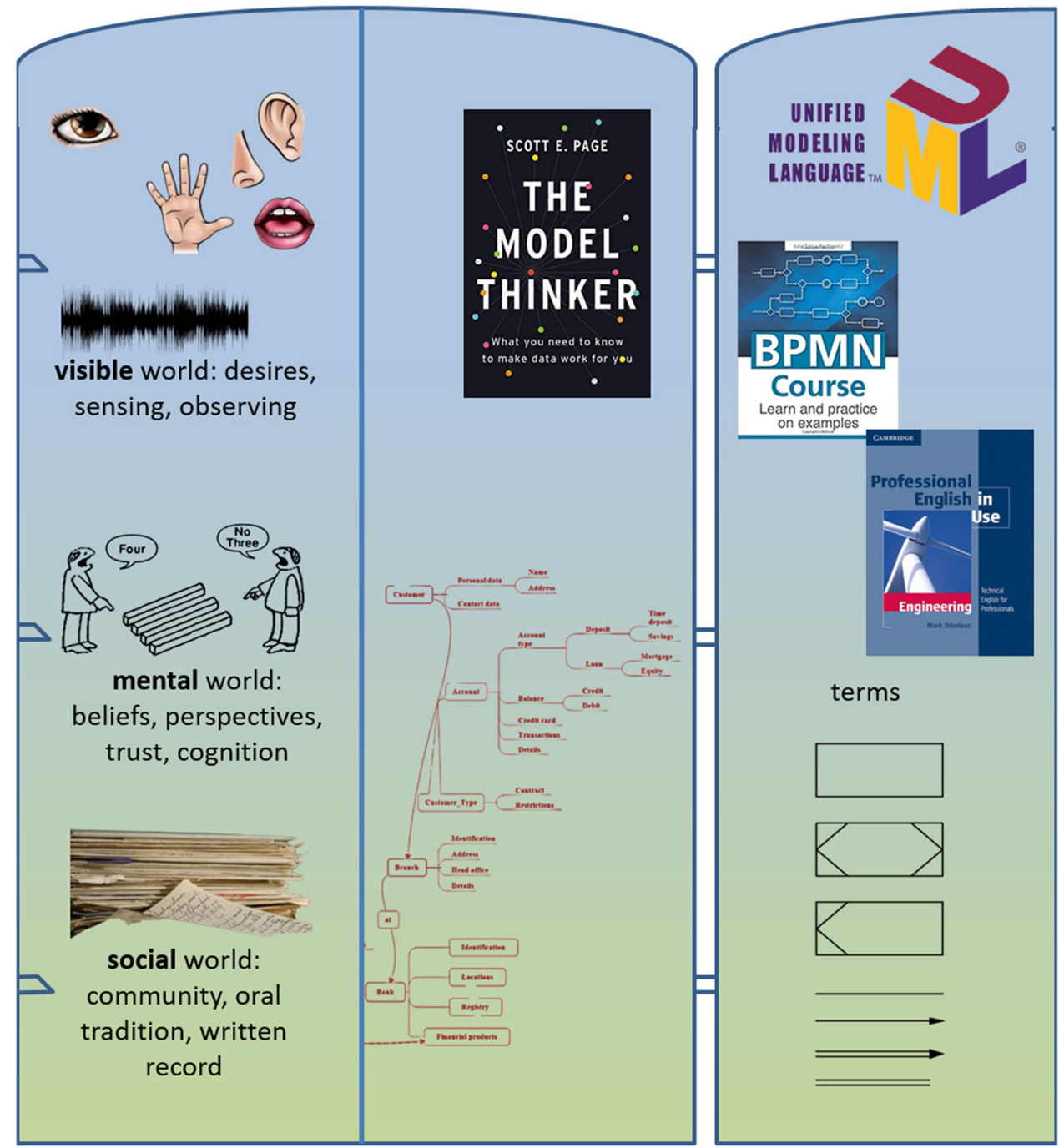

tional symbolic languages but also with modeling languages or model representation languages. The choice of language is a matter of preferences, education, and practices within the community of practice. Usually, ortho-normalized languages are used for this purpose, such as an entity-relationship language based on a common language foundation.

\section{The triptych with both wings opened: the conceptual} model perspective

Opening the left wing makes the world of conceptual modeling shine in all its beauty, as the left tableau now shows us a concept space whose elements are assigned to the models on the now fully opened middle tableau (see Fig. 5). The concept space brings order and structure to the world of observations, beliefs, agreements, etc., which we know are located on the back of the left wing. It may be organized by ontologies, thesauri, or other kinds of encyclopedias supporting conceptualization. We call this tableau the "encyclopedic tableau." It allows us to define the semantics and pragmatics of conceptual models and to relate the models to the human world.
Within this setting, the linguistic tableau supports conceptualization based on terms. We note that, apart from conceptual modeling, modeling does not need the encyclopedic tableau.

The triptych paradigm illustrates that conceptual modeling has three essential dimensions:

- The linguistic dimension: Conceptual modeling is made possible by a language that is generally accepted in a community of practice and that is semantically based on the perception and understanding of the members of the community of practice;

- The "encyclopedic" dimension: Conceptual models codify notions from the "user's encyclopedia" and express those through linguistic terms.

- The model dimension: Conceptual modeling connects the two other dimensions.

In other words: we base our consideration of conceptual models on a separation of (i) language, (ii) knowledge, personal 
Fig. 5 The open triptych. Left: The encyclopedic dimension for grounding models and their representation languages in concepts. Center: The conceptual model dimension. Right: The language dimension
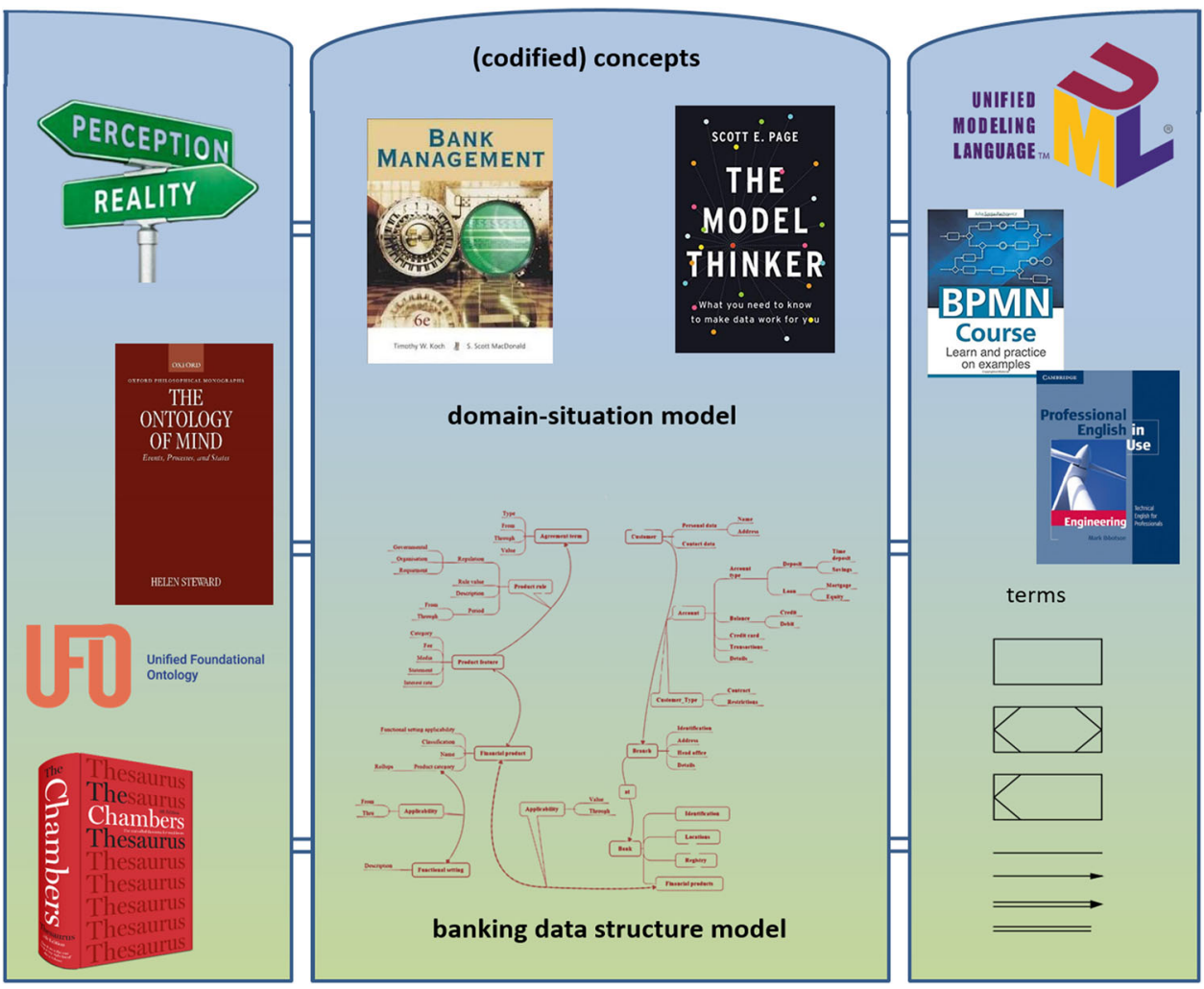

perception, and (iii) modeling as a separate activity. This separation allows us to distinguish between terms from certain languages and notions used for expressing perceptions or knowledge in the encyclopedic tableau and for enhancing models by concepts. It is thus the key to our distinction between models and conceptual models.

In Sects. 5.2-5.4, we discuss the three dimensions in detail.

\subsection{The linguistic dimension: the term space}

All forms of communication take place by means of terms, ${ }^{14}$ which are exchanged via a carrier medium (apart from metaphysical phenomena). Terms can be images or image sequences, sounds or tone sequences, texts or elements of a formal language, etc. and of course mixed forms. Term sets often consist of a set of basic forms (literals) from which more complex terms can be constructed based on grown or defined composition rules, i.e., a grammar. Think, for example, of natural languages, in which words, phrases, sentences, and texts are formed from the letters of the respective alphabet and some special characters. Or think of the score of a classical symphony: it consists of notes and special characters arranged along staves. The same applies to any formal language, such as the characters used in graph theory or UML.

\footnotetext{
14 As announced at the beginning of Sect. 2, we only use the word term instead of "sign" to avoid misunderstandings.
}

What all languages have in common is that they can only be properly used as a means of communication if

- the communication partners know the grammar, i.e., the literals and the composition rules: a person who cannot read notes cannot do anything with a score except perhaps admire it because it is calligraphically appealing;

- the terms used for content description have a relative similar meaning for all partners;

- the information content transported by a term is conscious and intended by the sender and can be accessed by the receiver $[5,37]$.

Communication thus requires that a community willing to communicate explicitly or implicitly agrees on the literals and character set rules used as well as on the assignment of meaning to terms. For example, with the first language acquisition of our mother tongue, we implicitly accept it as a means of communication and successively learn the available terms, how they are composed and what meaning is usually attributed to them. If such a means of communication comprises definitional elements, it can be used to create new language elements (e.g., new literals, new rules) and to define or propose their meaning, so that an agreement process can take place in the community: This corresponds to Gruber's original definition of ontology development ("shared conceptualization"). But we do not need full agreement. 
If we now consider the model characteristics discussed in Sect. 2, we can conclude that the essence of communication is the exchange of models based on terms. If there are rules about the composition and permissibility of the terms used, and if the represented models are associated with elements in the encyclopedic tableau, we speak of a controlled vocabulary.

\subsection{The encyclopedic dimension: the notion space}

People form a certain consolidated understanding of the world on the basis of their own cognition. Cognitive Scientists speak of a "cognitive structure"15 that is created by "cognitive processes" [20, 49]: observation and perception, and activities of thinking like comparison, reflection, idealization, context expansion, abstraction, and separation. Consequently, the main ingredients of a person's cognitive structure are ideas ${ }^{16}$ that are usually strongly interlinked.

The first level of the encyclopedic dimension is thus the cognitive structure of a person. In order to communicate about it, ideas and their connections must be represented and conveyed by terms of any language. A person who perceives such terms then interprets them according to her/his personal cognitive structure. This makes it clear that with this (traditional) form of communication, a complete agreement is not possible and cannot be proven.

However, the situation can be improved by externalizing the encyclopedic dimension and formalizing it in the form of explicit thesauri, lexicons, or ontologies. Explicating the encyclopedic dimension corresponds to the opening of the left wing of our triptych. For us, therefore, this externalization is the moment when ideas become concepts. I.e., we can now sharpen our understanding of "concept" and "notion" from Sect. 2 as follows:

1. A concept (in the encyclopedic dimension) is a mental construct

- that is formed by combining characteristics of general or abstract ideas gained by cognitive processes (see Sect. 2) and

- that is externalized and explicated in an encyclopedic structure. $^{17}$

\footnotetext{
15 Note that the term "cognitive structure" is used in the literature with different meanings. We use it here to denote the outcome of cognitive processes but not the structure of the processes. [49] calls this interpretation "conceptual structure."

16 We use "idea" here in the sense of "conception," which best relates to the German word "Vorstellung" [19, 56, 57], respectively, to "mental concepts" as used in [49].

17 Note that for externalization, a concept is assigned one term or a construct of terms.
}

2. Consequently, also a notion (being a general inclusive concept) is externalized and explicated in an encyclopedic structure.

If communication partners agree on the common use of such encyclopedic structures, for example, a shared [50] ontology, the probability of communication free of misunderstandings increases. However, it is of course still not possible to prove that the mutual understanding is identical.

\subsection{The conceptual model dimension: the link between term and notion spaces}

Usually, a concept space is specific to a certain area of application and is based on an understanding of the perceptions of things and coherences in that area. The utilization, exploration, and application of concepts depend on the user and her/his community of practice (e.g., users' education profile), usage, and context.

Based on what has been said so far, we can now formulate somewhat sloppily: A conceptual model selects, uses, reconsiders, orders, and integrates parts of a notion and a term space and thus establishes a structured view on that notion space (analogously, e.g., to views on databases).

Composition and structure of such a view correspond (according to CM7 and CM8, see Sect. 3) to the given conceptual model, which in turn is an extension of a certain metamodel (more precisely: of the metamodel elements and relationships) like the ER Model. The relationships may satisfy a number of axioms and lead to poly-hierarchically ordered concept structures, typically with layers. Such polyhierarchical structures arise in particular if the metamodel in question contains abstraction relations like generalization/specialization, aggregation/decomposition, clustering, and intension/extension, which can be instantiated on the model level.

The view, in turn, consolidates the meaning of the elements of the model and determines the linguistic meaning of terms (designators and annotations) which is an inherent but hidden aspect of the concept space.

Even though we have declared at the beginning not to present a (new) definition of "conceptual model," we cannot hold back from formulating our understanding of it here: $A$ conceptual model is a concise and purposeful consolidation of a set of concepts that are presented by means of terms in a predefined linguistic format. As such it establishes a view of a given notion space.

Let us explain all this using a very simple example, in which - for further simplification — we use a graphical grammar as known from UML for representation purposes on all levels except the lowest one, and have omitted an explicit definition of roles and multiplicities: 
Fig. 6 A simple metametamodel
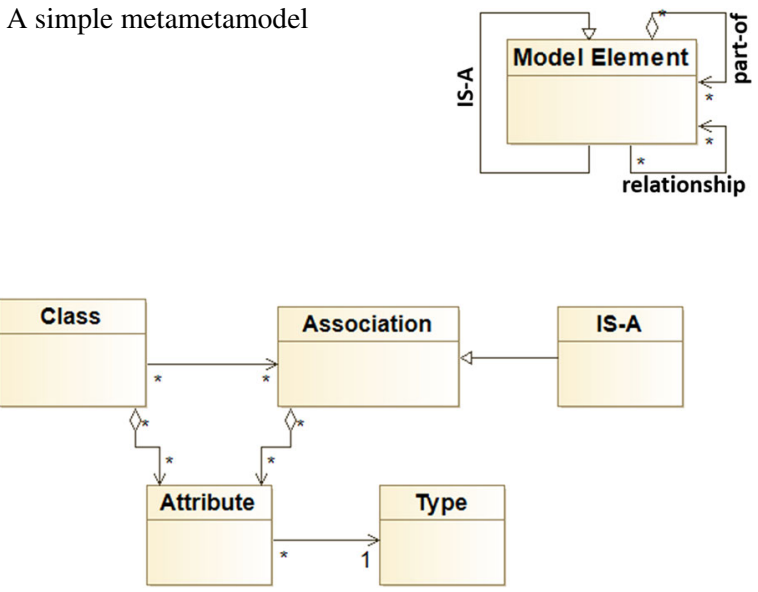

Fig. 7 A metamodel created as an extension of the metametamodel given in Fig. 6

(a) For creating a model, first of all, we have to define which modeling elements we want to use to build that model. This is done with the help of a metamodel. However, for metamodeling we need modeling elements again, so we have to create these on a Metameta level, i.e., hierarchy level $H^{3}$.

(b) Fig. 6 shows such very simple Metametamodel: it provides us with the possibility to define (in a metamodel) model elements that may be linked by IS-A, part-of and relation connectors. ${ }^{18}$

(c) Fig. 7 shows a metamodel that is an extension of the metametamodel of Fig. 6: it introduces the modeling elements Class, Association, IS-A, Attribute and Type as well as some relationships between these elements.

(d) Fig. 8 shows a model that refers to the retail sector as an application area. It is an extension of the metamodel given in Fig. 7. The model introduces classes Person and Organization and defines these as specializations (IS-A) of class Client which is associated with class Article in an m:n relationship. The classes have some attributes that come with type specifications for their extensions.

(e) Fig. 9 shows some extensions of the model given in Fig. 8 on the next lower level which is usually called object or data level. Here, we used a self-explanatory text-oriented grammar for representation.

Please note that nothing we have presented so far in our example can be called a conceptual model. Rather, we find ourselves-metaphorically speaking - in front of the triptych with open right and closed left wing. In other words, we are dealing with models

\footnotetext{
18 Figures 6,7 and 8 were created using the Modelio tool. https://www. modelio.org/.
}

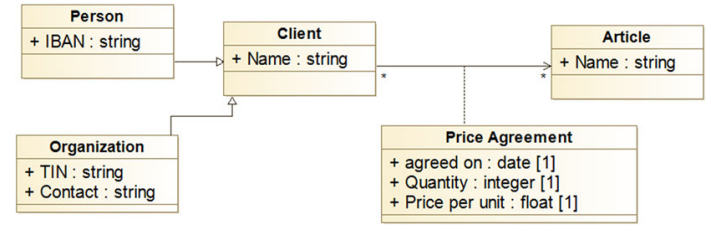

Fig. 8 A model created as an extension of the metamodel given in Fig. 7

- that are structured,

- are in intension/extension relationships, and

- have a certain intuitive meaning since we have used words from natural language and from the environment of UML.

However, the use of words, symbols, and structuring mechanisms that we know from conceptual modeling does not automatically lead to the creation of conceptual models. E.g., drawing an UML class diagram is not conceptual modeling per se.

To make the (meta-)models of Figs. 6, 7, 8, and 9 conceptual ones, we therefore have to associate concepts with each of their components. I.e., we need a notion space that explicates and explains the meaning of all elements (from "Model Element" down to "Price Agreement") on all levels including the connections/relationships.

It then becomes clear, that for instance if we associate with the components of the model given in Fig. 8 notions commonly used in the retail sector, this model defines a specific view on this sector in terms of its structure and the selection of what is considered relevant. We can also say that the conceptual model "codifies" the respective concepts of the application domain.

\subsection{Model and language hierarchies}

Model hierarchies are based on the duality of intension and extension $[3,25]$ and thus reflect levels of abstraction. They are well known through the considerations of Information Resource Dictionary systems [45] or the MetaObject Facility [46].

We, therefore, do not want to go into further details of model hierarchies in this paper. On the other hand, the model representation languages to be defined for this purpose deserve a closer look. They have to provide suitable syntactic artifacts to represent the semantic artifacts (the models).

These representation languages in turn form a hierarchy, which, however, is not isomorphic to the model hierarchy. Rather, we distinguish three levels as shown in Fig. 10 [36, 51]:

1. Grammar definition level (top level): contains the means of defining the language grammars. In our research, we use a specific version of the extended Backus Naur Form 
Fig. 9 Some extensions of the model given in Fig. 8

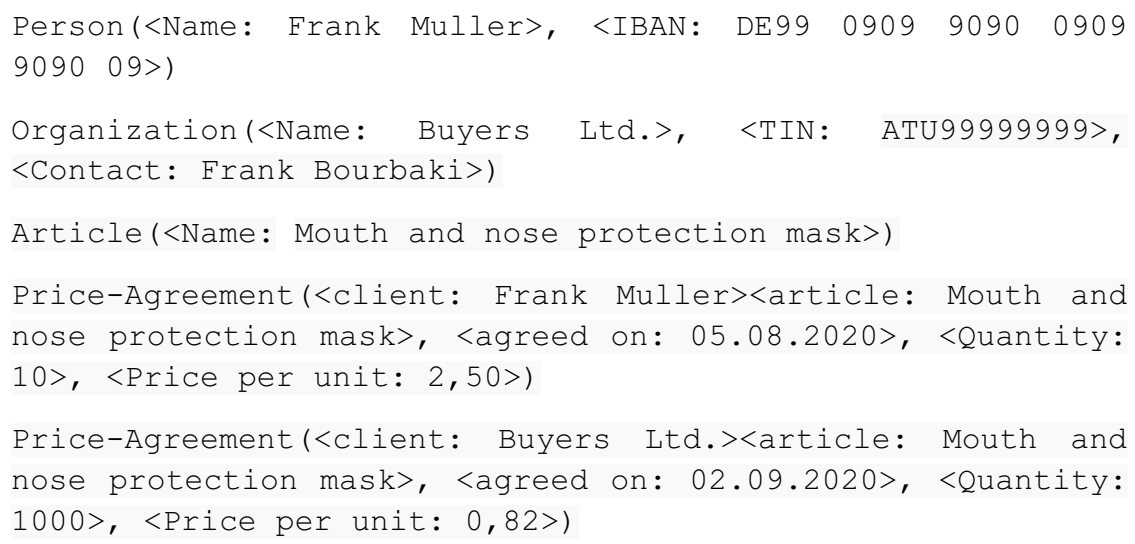

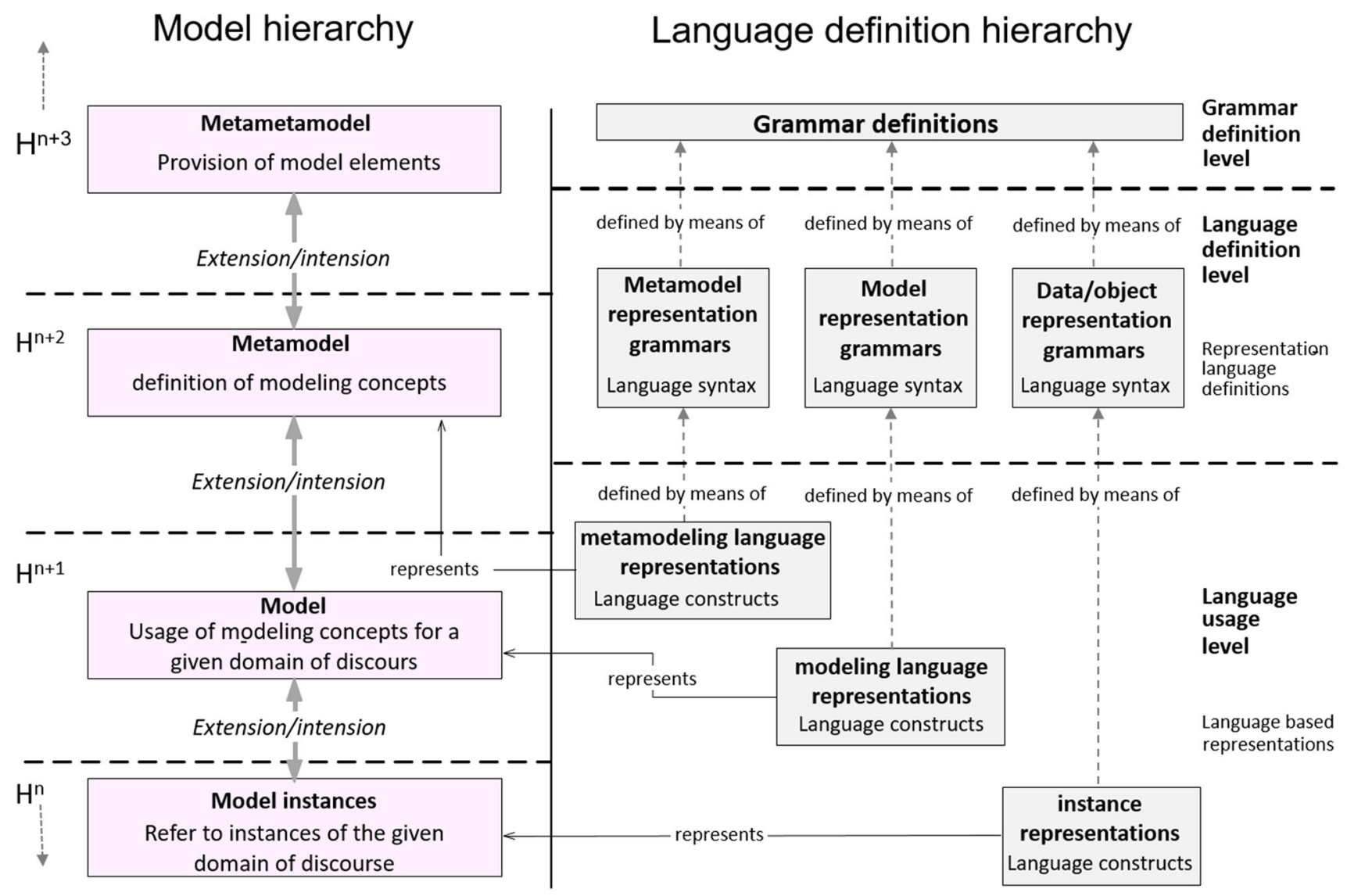

Fig. 10 Language hierarchy and its connections to the model hierarchy ( $\mathrm{A}^{\mathrm{i}}$ : abstraction level $i$ )

EBMF, compatible with the ANTLR grammar definition language [52].

2. Language definition level: defines grammars for the representation languages (RL) related to the (possibly domain-specific) modeling languages under consideration: metametamodel RLs, metamodel RLs, model RLs, and instance/data RLs.
3. Language usage level: representations of the models of all levels. For example, it is possible to use OWL 2 as a representation language at this level. 


\section{Conclusion and future research}

Modeling is as old as a human advanced civilization. The bible remembers models already in the Chronicles $(1,28$, $11)^{19}$ or Torah/Genesis (2 Moses, 25, 9 or 1 Moses, 1, 27). Around the same time, Heraclitus developed the tenet of logos that consists of concepts.

Conceptual modeling is one of the kernel activities in information systems engineering. For instance, conceptual schemata are widely used since the advent of database technology and explicitly named as such with the introduction of the entity-relationship modeling language. The first model we know that might be called a conceptual one relates back to the myth of Ptah who builds the world according to his worldview and doctrine. As far as we know for sciences, simulation explicitly uses the term "conceptual model" since 1950 [53]. Other disciplines use the wording "conceptual model" with a quite different meaning, see for instance [54].

Today, the term "conceptual model" is widely used and needs proper systematization. We start this systematization with eight characteristics for a signature of the conceptual model. The first six characteristics (related to origins; concern and usage; purpose and function; domain and context; focus; representation) already belong to the signature of models. These characteristics are extended for conceptual models by two additional characteristics (concept space; concept relationship). The second and third characteristics are extended for conceptual models.

We differentiate between notions as general inclusive concepts, terms as representations referring to concepts, and concepts in the narrow sense as codified abstract ideas. In systems engineering, concepts are those in the narrow sense. The histories of notions, concepts, and terms are different. Notions have been used as reasoning instruments. Terms are bound to languages. Concepts have a history of at least 3-4000 years. The separation into notions, concepts, and terms can be used for a proper introduction of a paradigm of conceptual modeling: the triptych that consists of three wings which represent

1. the notion or "encyclopaedic" dimension as the supporting foundation of concepts,

2. the term or linguistic dimension as the enabler for model specification, and

3 . the concept and model dimension as the result of modeling.

The outer two wings can be used without the third one. They form then a closed triptych, i.e., a diptych. The middle part of the triptych - the model dimension-is supported by the

\footnotetext{
19 The Zwingli bible translation explicitly uses the word "Modell," whereas the Luther translation uses "Vorbild" (antetype, archetype).
}

"encyclopaedic" dimension and is enabled by the linguistic dimension.

Modeling has been systematized by abstraction levels. The separation by abstraction is typical for artificial languages. The ground $H^{n}$ level represents things of interest. The $H^{n+1}$ level is used for models; the $H^{n+2}$ level for metamodels (i.e., essentially the structure of the modeling approach), and the $H^{n+3}$ for metametamodels (i.e., essentially the framework of the modeling approach). This strict separation by abstraction is blurred in the linguistic dimension and almost not existing in the "encyclopedic" dimension. Conceptual modeling thus supports defining properly structured views on the encyclopedic dimension.

We did not plan to propose a new definition of the term "conceptual model," especially as more than 60 such definitions exist to our knowledge. The introduced signature, however, together with the Triptych paradigm provides a means and explanation of the essence of conceptual modeling. We understand this as the first step toward a general theory of conceptual modeling. We encounter a good number of problems to be solved in forthcoming research. The list below is ordered according to our plans for the future; collaboration and contribution from the community are more than welcome:

1. Modeling is based on abstraction, modularity, and other modeling principles. The selection of promising and useful principles is still an art that compromises between model capacity, cognitive economy for the community of practice, and inferential utility. We need a proper systematization of principles. Abstraction goes beyond structural abstraction (e.g., [42]) and considers advanced hierarchies beyond IsA relationships.

2. Conceptual model characteristic 7 relates models to their concept space. The theory of conceptual spaces distinguishes concepts, notions, and terms. The corresponding spaces need a deeper exploration. Classical intension-extension Galois lattices are too strict for terms and notions.

3. Conceptual models use languages as enablers. In natural languages, words or terms have their language specific semantic (or word) fields, i.e., a lexical set of words that share a common semantic property [55]. These fields can be different for different languages. Conceptual modeling is not bound to a singleton language. Multi-language modeling can be based on synset approaches commonly used for WordNet.

4. Similar to generic models which allow specialization of models to more appropriate ones, concept spaces can also be based on generic concept spaces with a specialization theory that allows to adapt the concept space to a specific application, context, and community of practice. 
5. Conceptual model characteristic 8 is based on concept relationship. There may be various types of relationships such as one-to-one or many-to-one. Concept spaces are typically structured. The impact of this variability is an open issue.

6. Modeling is steered by the purpose and function of the model. We know so far a good variety of model functions in different scenarios where models are used on purpose. Functions can be categorized. This categorization can be used for categorization of conceptual models and for stereotyping of models. These stereotypes have then a common grounding and basis that is inherited by most models of such a stereotype.

7. We typically use a number of models of the same origins in a coherent manner. Some models are derived from other models in such model ensemble. Conceptual model transformation, model coexistence, and model coevolution need a theoretical underpinning.

8. The focus of a conceptual model is based on the directed and concentrated attention that is steered from one side by the model's function and purpose and from the other side by the potential and capacity of the encyclopedic support and enabling language. The impact of these governing dimensions needs a proper exploration.

9. We considered so far the four most important concerns and usages. There are further concerns and usages which result in different kinds of conceptual models, specific quality requirements to conceptual models, and specific variability of the model. A model is also serving a weighted overlaying combination of concerns and usages.

10. Conceptual models do not reflect all potential origins of a given universe of discourse but only most likely or most typical ones. Whether the selection of such a set of origins is the most appropriate for a given modeling target is a difficult question. Models can also be origins of models, e.g., mental models and domain models. The plasticity and stability of a model against the selection of origins is a difficult research issue.

11. Applications, infrastructures, origins, and user communities continuously evolve. Evolution of models needs a proper modernization strategy, evolution tactics, and a realization approach including handling of heritage (legacy) models. Models will become adaptable and self-adapting.

12. The context of (conceptual) models and of (conceptual) modeling includes aspects of time, disciplines, (thought) schools, applications, experience, education, and in general of cultures. Models differ in dependence on this context. We need powerful transformation techniques that allow to become partially contextindependent.
13. Can recommendations for the development of domainspecific conceptual modeling methods be derived from all this?

This list is far from being complete. It demonstrates, however, the potential of the signature approach by a systematic treatment of open issues in (conceptual) model research.

Funding Open access funding provided by Universität Klagenfurt.

Open Access This article is licensed under a Creative Commons Attribution 4.0 International License, which permits use, sharing, adaptation, distribution and reproduction in any medium or format, as long as you give appropriate credit to the original author(s) and the source, provide a link to the Creative Commons licence, and indicate if changes were made. The images or other third party material in this article are included in the article's Creative Commons licence, unless indicated otherwise in a credit line to the material. If material is not included in the article's Creative Commons licence and your intended use is not permitted by statutory regulation or exceeds the permitted use, you will need to obtain permission directly from the copyright holder. To view a copy of this licence, visit http://creativecomm ons.org/licenses/by/4.0/.

\section{References}

1. Petri, C.A.: Fundamentals of a theory of asynchronous information flow. In: Proceedings of the 2nd IFIP Congress 1962, pp. 386-390. North-Holland, Berlin (1962)

2. Plexousakis, D., Patkos, T.: Modeling knowledge action and time: action theories and their application in dynamic domains. NEMO Summer School 2019, University of Vienna, Faculty of Computer Science, Vienna (2019)

3. Kangassalo, H. (2017) Definitional conceptual schemata-the core for thinking, learning, and communication. Keynote given at 25th EJC Conference, Maribor, Slovenia (June, 2017)

4. Thalheim, B.: Conceptual model notions-a matter of controversy: conceptual modeling and its lacunas. EMISA Int. J. Concept. Model. 9-27, 2018 (2018)

5. von Foerster, H.: Perception of the future and future of perception. Instr. Sci. 1(1), 31-43 (1972)

6. von Foerster, H.: Zur Konstruktion der Wirklichkeit. Die erfundene Wirklichkeit. Wie wissen wir was wir zu wissen glauben, pp. 39-60 (1991)

7. Mylopoulos, J.: Philosophical Foundations of Conceptual Modeling: What is a Conceptual Model? ER Online Summer Seminars. https://eross2020.inf.unibz.it/wp-content/uploads/2020/07/ UniBZ-John.pdf. Accessed August 3rd, 2020

8. Delcambre, L.M.L., Liddle, S.W., Pastor, O., Storey, V.C.: A reference framework for conceptual modeling. In: Proceedings of the ER 2018, Volume 11157 of Lecture Notes in Computer Science, pp. 27-42. Springer, Berlin (2018)

9. Guarino, N., Guizzardi, G., Mylopoulos, J.: On philosophical foundations of conceptual models. In: Information Modeling and Knowledge Bases XXXI, Frontiers in Artificial Intelligence and Applications, forthcoming. IOS Press, New York (2020)

10. Kleppe, A.G., Warmer, J.B., Bast, W.: MDA Explained: The Model Driven Architecture: Practice and Promise. Addison-Wesley Longman Publishing Co., Inc., New York (2003)

11. Brand, T., Giese, H.: Towards software architecture runtime models for continuous adaptive monitoring. In: Proceedings of the MODELS 2018 Workshops, vol. 2245 of CEUR Workshop Proceedings, pp. 72-77 (2018) 
12. France, R., Rumpe, B.: Model-driven development of complex software: a research roadmap. In: Future of Software Engineering, 2007, 37-54. IEEE Computer Society, New York

13. Gray, J., Rumpe, B.: Models as the subject of research. Softw. Syst. Model. 18(6), 3189-3191 (2019)

14. Pastor, O., Ruiz, M.: From requirements to code: a conceptual model-based approach for automating the software production process. EMISA Int. J. Concept. Model. 2018, 274-280 (2018)

15. KEA-Mod: Kompetenzorientiertes E-Assessment für die grafische Modellierung—Projektvorstellung. https://butler.aifb.kit.edu/ MoHoL2020/KEA-Mod.pdf. Accessed August 3rd, 2020

16. Thalheim, B.: Conceptual Modeling Foundations: The Notion of a Model in Conceptual Modeling. In Encyclopedia of Database Systems. Springer, New York (2019)

17. Thalheim, B., Nissen, I. (eds.): Wissenschaft und Kunst der Modellierung: Modelle, Modellieren. Modellierung. De Gruyter, Boston (2015)

18. Thalheim, B., Nissen, I.: Ein neuer Modellbegriff. In Wissenschaft und Kunst der Modellierung: Modelle, Modellieren, Modellierung, pp. 491-548. De Gruyter, Boston (2015)

19. Twardowski, K.: Zur Lehre vom Inhalt und Gegenstand der Vorstellungen: Eine psychologische Untersuchung. Hölder, Wien (1894)

20. von Foerster, H.: Understanding Understanding: Essays on Cybernetics and Cognition. Springer, New York (2003)

21. W3C: Semantic Web. https://www.w3.org/standards/ semanticweb/. Accessed on August 13, 2020

22. Merrian-Webster Dictionary: https://www.merriam-webster.com/ dictionary/. Accessed on August 3rd, 2020

23. Wikiquote: Conceptual model. https://en.wikiquote.org/wiki/ Conceptual_model. 2017. Accessed Nov. 21, 2017

24. Miller, G.A., Beckwith, R., Fellbaum, C., Gross, D., Miller, K.: Wordnet: an on-line lexical database. Int. J. Lexicogr. 3, 235-244 (1990)

25. Brodie, M., Mylopoulos, J., Schmidt, J.W. (eds.): On Conceptual Modeling. Springer, Heidelberg (1986)

26. Murphy, G.L.: The Big Book of Concepts. MIT Press, Berlin (2001)

27. Mahr, B.: Was ist ein Modell. Der Modellbegriff in Natur-und Ingenieurwissenschaften“. TU Berlin Summer term 2005, https://pdv. cs.tu-berlin.de/gk-magsi/RV05Mahr.pdf. Accessed on August 3rd, 2020

28. Stachowiak, H.: Allgemeine Modelltheorie. Springer, Berlin (1973)

29. Mahr, B.: Modelle und ihre Befragbarkeit-Grundlagen einer allgemeinen Modelltheorie. Erwägen-Wissen-Ethik (EWE) 26(3), 329-342 (2015)

30. Mahr, B.: Cargo. Zum Verhältnis von Bild und Modell. In Visuelle Modelle, 17-40. Wilhelm Fink Verlag, München (2008)

31. Michael, J., Mayr, H.C.: Conceptual modeling for ambient assistance. In: Proceedings of the ER 2013, LNCS, vol. 8217, pp. 403-413. Springer, Berlin (2013)

32. Michael, J., Mayr, H.C.: The process of creating a domain specific modeling method (extended abstract). In: Proceedings of the \{EMISA 2016, vol. 1701 of CEUR Workshop Proceedings, pp. 40-43. CEUR-WS.org (2016)

33. Wolters, G.: Modell. In: Mittelstraß, J. (ed.) Enzyklopädie Philosophie und Wissenschaftstheorie, vol. 2, pp. 911-913. J.B. Metzler, Mannheim (1995)

34. Miller, G.A.: The science of words. Scientific American Library, New York (1991)

35. Sendall, S., Kozaczynski, W.: Model transformation: the heart and soul of model-driven software development. IEEE Softw. 20(5), 42-45 (2003). https://doi.org/10.1109/MS.2003.1231150

36. Mayr, H.C., Michael, J., Ranasinghe, S., Shekhovtsov, V.A., Steinberger, C.: Model centered architecture. In: Cabot, J., Gómez, C., Pastor, O., Sancho, M., Teniente, E. (eds.) Conceptual modeling perspectives, pp. 85-104. Springer, Berlin (2017). https://doi.org/ 10.1007/978-3-319-67271-7_7

37. von Foerster, H., von Glasersfeld, E., Hejl, P.: Einführung in den Konstruktivismus. Piper, München (1992)

38. Chen, P.P.: The entity-relationship model: toward a unified view of data. ACM TODS 1(1), 9-36 (1976)

39. Kant, I.: Kritik der reinen Vernunft. Verlag von Johann Friedrich Hartknoch, Riga (1781/87)

40. Lattmann, C.: Vom Dreieck zu Pyramiden-Mathematische Modellierung bei Platon zwischen Thales und Euklid. Habilitationsschrift, CAU Kiel (2017)

41. Platon, R.: Platonis rempublicam recognovit brevique adnotatione critica instruxit. Oxford (2003)

42. Smith, J.M., Smith, D.C.P.: Database abstractions: aggregation and generalization. ACM TODS 2(2), 105-133 (1977)

43. Lockemann, P.C., Moerkotte, G., Neufeld, A., Radermacher, K., Runge, N.: Database design with user-definable modeling concepts. Data Knowl. Eng. 10, 229-257 (1993)

44. Lockemann, P.C., Mayr, H.C., Weil, W.H., Wohlleber, W.H.: Data abstractions for database systems. ACM Trans. Database Syst. 4(1), 60-75 (1979)

45. ISO/IEC 10027:1990(en). Information technology-Information Resource Dictionary System (IRDS) framework (1990)

46. MetaObject Facility Specification: https://www.omg.org/mof/. Accessed August 10th, 2020

47. Lockemann, P.C., Mayr, H.C.: Rechnergestützte Informationssysteme. Springer, Berlin (1978)

48. Schema.Org Community Group. Welcome to schema.org. https:// schema.org/ (2019)

49. Koltko-Rivera,M.E.: What are cognitive structures? Are worldviews cognitive structures? In: Proceedings of the 115th-Annual Convention of the American Psychological Association, San Francisco (2007)

50. Gruber, T.R.: Toward principles for the design of ontologies used for knowledge sharing. Int. J. Hum. Comput. Stud. 43, 907-928 (1993)

51. Mayr, H.C., Michael, J., Shekhovtsov, V.A., Ranasinghe, S., Steinberger, C.: A model centered perspective on software-intensive systems. In: Proceedings of the 9th International Workshop on Enterprise Modeling and Information Systems Architectures, CEUR, vol. 2097, pp. 58-64 (2018).

52. Parr, T.: The Definitive ANTLR 4 Reference. The Pragmatic Bookshelf (2013)

53. Robinson, S., Arbez, G., Birta, L.G., Tolk, A., Wagner, G.: Conceptual modeling: definition, purpose and benefits. In: Proceedings of the of the 2015 Winter Simulation School, pp. 2812-2826. IEEE, New York (2015)

54. Shreffler-Grant, J., Nichols, E., Weinert, C.: The Montana State University conceptual model of complementary and alternative medicine health literacy. https://www.researchgate. net/publication/253331927_The_Montana_State_University_ Conceptual_Model_of_Complementary_and_Alternative_ Medicine_Health_Literacy. Accessed September 3, 2020

55. Brinton, L.J.: The Structure of Modern English: A Linguistic Introduction. John Benjamins Publishing Company, London (2000)

56. Bolzano, B.: Wissenschaftslehre: Versuch einer ausführlichen und größtenteils neuen Darstellung der Logik. Seidel, Sulzbach (1837)

57. Brentano, F.: Psychologie vom empirischen Standpunkte. Dunker \& Humblot, Leipzig (1874)

58. Klaus, G., Buhr, M. (eds.): Philosophisches Wörterbuch. Bibliographisches Institut, Leipzig (1971)

Publisher's Note Springer Nature remains neutral with regard to jurisdictional claims in published maps and institutional affiliations. 


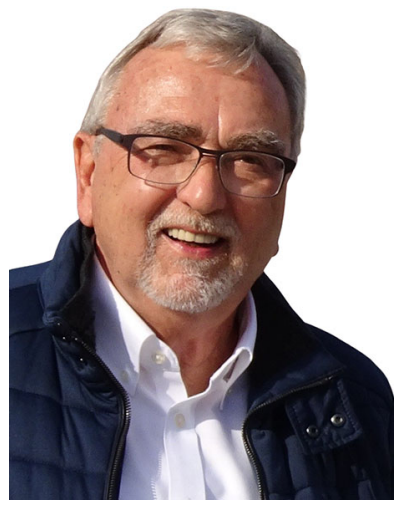

Heinrich C. Mayr has been full professor of Informatics at Universität Klagenfurt and head of the research group Application Engineering since 1990. Until then he was assistant professor at the University of Karlsruhe (today: KIT), visiting professor at several universities, and managing director of a German software company. His research includes methods of information system design, requirements engineering and modeling, and knowledge management. Among other functions, he has served as President of the Gesellschaft für Informatik GI, Vice President of the Council of European Professional Informatics Societies CEPIS, and Chairman of the ER Steering Committee. He also served as Rector of his university for 6 years. Currently, he is editor-in-chief of the "Lecture Notes in Informatics," chairman of the council of the Software Internet Cluster SIC, member of the supervisory board of the Carinthian Investment Administration, and an ER Fellow since 2013.

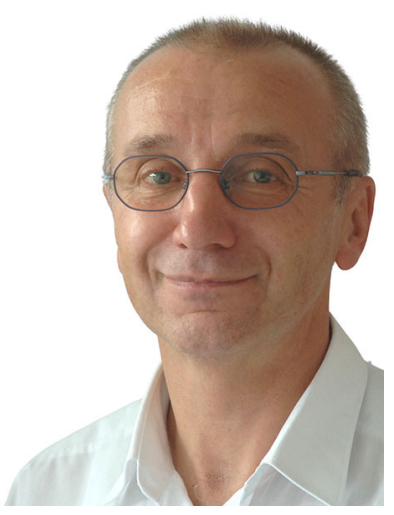

Bernhard Thalheim has been full professor of Computer Science at Christian-Albrechts Universität Kiel from 2003 till 2020. He chaired database and information system groups since 1993. He was a professor in Dresden, Kuwait, Rostock, and Cottbus since 1986. His work was awarded the P.P. Chen award by Elsevier in 2008. Since 2009, he is an ER fellow. $\mathrm{He}$ is also the honorary Kolmogorov chair at Lomonossov University at Moscov in Russia since 2005. He has held visiting professor positions in America, Asia, Europe, and New Zealand. His main research area is (conceptual) modeling and its foundation. He is also interested and researching in database technology, database programming, (distributed) object-relational information systems, business informatics, web information systems, performance tuning and forecasting, data mining, data warehouses and OLAP foundations, content management, database and information systems theory, database systems and software architecture, discrete mathematics, and logics. He has been dean, president of senates and convents, head of departments, and co-chair of threescore conferences. 